\title{
BMJ Open Implementing professional behaviour change in teams under pressure: results from phase one of a prospective process evaluation (the Implementing Nutrition Screening in Community Care for Older People (INSCCOPe) project)
}

\author{
Mike Bracher, ${ }^{01,2}$ Katherine Steward, ${ }^{3}$ Kathy Wallis, ${ }^{4}$ Carl R May, \\ Annemarie Aburrow, ${ }^{4}$ Jane Murphy ${ }^{6}$
}

To cite: Bracher M, Steward K, Wallis $\mathrm{K}$, et al. Implementing professional behaviour change in teams under pressure: results from phase one of a prospective process evaluation (the Implementing Nutrition Screening in Community Care for Older People (INSCCOPe) project). BMJ Open 2019;9:e025966. doi:10.1136/ bmjopen-2018-025966

- Prepublication history and additional material for this paper are available online. To view these files, please visit the journal online (http://dx.doi. org/10.1136/bmjopen-2018025966).

Received 14 August 2018

Revised 30 April 2019

Accepted 01 July 2019
Check for updates

(C) Author(s) (or their employer(s)) 2019. Re-use permitted under CC BY-NC. No commercial re-use. See rights and permissions. Published by BMJ.

For numbered affiliations see end of article.

Correspondence to

Dr Mike Bracher;

m.j.bracher@soton.ac.uk

\section{ABSTRACT}

Objectives To evaluate the implementation of a new procedure for screening and treatment of malnutrition for older people in community settings and to identify factors promoting or inhibiting its implementation as a routine aspect of care.

Design Prospective process evaluation using mixed methods with pre/post-implementation measures.

Setting and participants Community teams (nursing and allied health professionals) within a UK National Health Service Community Trust. 73 participants were recruited, of which 32 completed both pre-implemetation and postimplementation surveys.

Main outcome measures NoMAD survey for pre-postintervention measures; telephone interviews exploring participant experiences and wider organisational/ contextual processes.

Methods Data prior to implementation of training, baseline (T0-survey and telephone interview) and 2 months following training (T1-follow-up survey). Quantitative data described using frequency tables reporting team type, healthcare provider role group and total study sample; analysis using Wilcoxon rank-sum (subgroup comparison) and Wilcoxon signed-rank (withingroup observation point comparison) tests. Qualitative interview data (audio and transcription) analysed through directed content analysis using normalisation process theory.

Results High support for nutrition screening and treatment indicated by participants. Concerns expressed around logistical, organisational and specialist dietetic support. Pre-post-training measures indicated a positive impact of training on knowledge of the new procedure; however, most implementation measures saw no significant changes between time points or between subgroups (training participants vs non-participants). Implementation barriers included the following: high levels of training non-completion; vulnerability to attrition of trained staff; lack of monitoring of postintervention compliance and lack of access to dietetic support.
Strengths and limitations of this study

- Prospective investigation of factors promoting or inhibiting implementation of service development, allowing for feedback to inform ongoing development of the programme.

- To our knowledge, this is the first time that a prospective process evaluation has been conducted specifically on implementation of nutritional care in community settings process evaluations conducted on implementation of nutritional care in community settings.

- Integrated use of mixed methods to provide reproducible measures at each observation point (quantitative, survey), and explore processes underpinning them (qualitative, semistructured telephone interviews).

- Lack of quota sample due to lack of data on workforce composition may mean that sample is unrepresentative of the role/seniority profile of the target population.

- Limitations of the study include the following: lack of observation of new procedures applied in situ, meaning that processes relating to implementation can only be explored retrospectively through interviews, and therefore recall and response bias may affect the data; lack of available data on composition of the target population (ie, the area of the organisation in which the intervention was implemented) limits reporting on representativeness of the study sample.

Conclusion Greater support necessary to support implementation in relation to monitoring of training completion, and organisational support for nutrition screening and treatment activity. Recommended changes to implementation design are as follows: appointment of a key person to support and monitor procedure compliance; adoption of training as an e-learning module within the 
existing organisational platform to increase participation in changeable working conditions.

\section{BACKGROUND}

Implementation of new procedures or technologies in healthcare settings involves complex processes, bringing together individuals of different professional groups in varied kinds of work. ${ }^{12}$ Process evaluation studies help us understand the success or failure of interventions, and illuminate factors that shape intervention outcomes. ${ }^{34}$ The dynamics of practice implementation in open systems, like community health and social care-is poorly understood. Implementation conditions in community settings are different from those of closed systems (secondary/ hospital settings) because of the spatial distribution of service users and healthcare providers, and their focus on domiciliary screening and care. Contextual factors such as funding, resource and staffing pressures, which may have consequences that differ from those found in hospitals. $^{56}$

Screening for malnutrition represents an important aspect of routine community care for those working with older people $\mathrm{e}^{7-9}$; however, malnutrition is often undiagnosed and frequently under-recognised. ${ }^{10}$ Previous studies in hospital and care home settings indicate that contextual and organisational barriers can impede introduction of new nutritional care procedures. ${ }^{11} 12$ To our knowledge, no published studies have focused specifically and prospectively on nutrition screening implementation in community settings. This paper contributes to understanding professional behaviour change in community settings through results from the implementation phase of a new malnutrition screening and care procedure for community teams working with older people.

\section{Prevalence, impact and economic costs of malnutrition}

We use the term 'malnutrition' to refer to 'undernutrition', although the term 'malnutrition' can encompass both overnutrition/obesity and undernutrition. ${ }^{13} 14$ Malnutrition is defined as a state in which a deficiency, excess or imbalance of energy, protein and other nutrients causes measurable adverse effects on tissue/body form (body shape, size and composition), function or clinical outcome. ${ }^{15}$ Over threemillion individuals are estimated to be malnourished or at risk of malnutrition in the UK, the majority $(93 \%)$ living in the community, ${ }^{16} 17$ of which over one million are aged above 65 years. ${ }^{18}$ Malnutrition has consequences that both affect individuals and impose a strain on healthcare resources through delayed recovery from illness, increased need for healthcare provision at home, more frequent visits by nurses, and a greater number of hospital admissions. ${ }^{10} 1319$ Evidence suggests that malnutrition in older people can be prevented through screening and early intervention, and that benefits of treating malnutrition far outweigh costs. $^{20}$
A new procedure for screening and treatment of malnutrition (the intervention)

There is good evidence to suggest that nutrition screening of older people living in the community together with appropriate intervention and monitoring improves nutritional status. ${ }^{21}$ Healthcare staff providing care and treatment within community settings (both physical and mental healthcare), who already review and manage older people, are well placed to perform nutrition screening in routine practice (in accordance with guidelines from the UK National Institute for Clinical Excellence). ${ }^{9} 22$ The feasibility of introducing a validated screening tool and nutrition resource kit has been shown in older adults attending general practices in an Australian study. ${ }^{23}$ In the UK, local protocols concerning nutritional screening and assessment often exist within National Health Service (NHS) hospital trusts, based on national protocols. However, previous service development work around nutrition in the community indicates that it is often not considered a routine part of interactions with older people. ${ }^{24}$ Leading on from this service development project, we were alerted to the current situation across a local NHS Community Trust where nutritional care was only intermittently implemented (particularly the use and follow-up of good care plans) due to other priorities of care and lack of awareness of the issue. This highlighted the need to change practice in delivery of nutritional care for older people across the community.

We report on the implementation phases of a new procedure for screening and treatment of malnutrition in older people within an NHS Community Trust in England. We focus on the work of community nursing and allied health professionals (covering physical and mental health services, respectively), mobilising this procedure in the community (see online supplementary additional file 1).

Existing organisational policy within the Trust has established when patients should be screened for malnutrition, and care that they should receive depending on malnutrition risk (assessed by Malnutrition Universal Screening Tool-'MUST' screening). ${ }^{7}$ The new procedure introduced several updates to existing policy: first, only patients at medium risk or high risk of malnutrition (those with a 'MUST' score of 1 or more) require monthly re-screening and follow-up (previously all patients were expected to receive monthly screening), while patients at low risk are now re-screened annually, unless there is a significant change in their health status. Second, a nutritional pathway including appropriate care planning actions to be taken depending on risk level and each specific case, including provision of malnutrition information resource sheets to medium-risk and high-risk patients as a mandatory activity (previously these were not routinely provided to patients in these categories). New information resources were produced and guidance for when to use existing resources was specified within the new procedure. Third, the electronic patient records system allows storage of screening information for malnutrition 
in one place (previously paper and electronic processes ran separately and in parallel). Prior to implementation of this electronic system, concerns had been raised regarding storage and availability of screening information to inform treatment and care planning. Within the new procedure, a form was generated within the electronic system to record screening results and enable care planning activity. Fourth, the new procedure emphasised that community care staff at all roles and grades working with older people have responsibility for malnutrition screening and delivery of appropriate treatment. Introduction of the new procedure was provided through staff training delivered by a registered dietitian. In all, 12 sessions were offered to enable as many staff as possible to attend a 1-hour training session. Immediate effectiveness of training was assessed through pre-and-post-training knowledge check questionnaires.

\section{The role of normalisation process theory}

This study is informed by normalisation process theory (NPT), which identifies, characterises and explains mechanisms that motivate and shape implementation processes. ${ }^{2526}$ NPT focuses on three aspects of implementation processes: how components of complex interventions confer particular capabilities on their users; what the work of implementing, embedding and integrating these capabilities in everyday practice is, and how intervening mechanisms (coherence, cognitive participation, collective action and reflexive monitoring) motivate and shape implementation processes and explain their operation; and finally, how participants in implementation processes mobilise structural and cognitive resources as they invest in them. ${ }^{25}$ NPT is now widely used to inform process evaluation research, a recent systematic review shows 130 reports of feasibility studies and process evaluations of controlled and uncontrolled interventions in open and closed systems, most of these published in the last 5 years. ${ }^{26}$

NPT has been used in two previous studies focused on development the role of the nurse as a link advisor for research and champion for nutrition in the neonatal intensive care unit ${ }^{27}$ and implementing nutrition guidelines for older people in residential care homes. ${ }^{12}$ However, the present study is the first to apply this to implementation of procedures for screening and treatment of malnutrition in community settings. The theory can be used prospectively (ie, to identify potential areas of importance with respect to embedding and implementation within a given topic area) and retrospectively (ie, to analyse existing processes, practices and technologies with respect to social and organisational activities relating to implementation and embedding). ${ }^{28} 29$ NPT does not provide a framework of causal prediction; rather, its intended use has been to help anticipate the trajectory of a new practice, technology or process, with respect to success of implementation and embedding in routine practice (ie, given attention to activities in areas identified in the framework, whether implementation and embedding is more or less likely to be successful).$^{25}$

\section{The relationship between implementation of the new procedure and the process evaluation}

Complex relationships often exist between those implementing service development in healthcare and those evaluating these processes. ${ }^{30}$ In some cases, both kinds of work are undertaken by the same people, ${ }^{11}$ whereas in others the process evaluation may be undertaken by those not involved in either initial development or implementation of interventions. ${ }^{31}$ In both cases, findings from process evaluations commonly inform ongoing development of implementation strategies. ${ }^{26}$ It is therefore necessary to define the relationship between these two kinds of work within the current project. Implementation and embedding ('normalisation') of the new procedure for screening and treatment of malnutrition was the focus of this process evaluation. Development and implementation of the procedure was led by KS with input from $\mathrm{AA}$ and other colleagues within the implementation site (see online supplementary additional file 1). Process evaluation work was undertaken primarily by MB, JS, KW and CRM, with input from KS and AA relating to recruitment strategy. Findings from the process evaluation were provided to the procedure development and implementation team following completion of $\mathrm{T} 1$ data collection, to inform ongoing development.

\section{AIMS AND OBJECTIVES}

The process evaluation was entitled: Implementing Nutrition Screening in Community Care for Older People (INSCCOPe). The aim of the study was (i) to undertake a process evaluation of implementation of the screening procedure and its associated training and (ii) identify factors promoting or inhibiting embedding of nutritional screening in routine care. Outcomes relating to clinical effectiveness of the new procedure were assessed by the procedure development and implementation team and will be reported separately. Outcomes relating to processes affecting implementation and embedding are the focus of this process evaluation, and methods for investigation are now described.

\section{METHODS}

\section{Exclusion and inclusion criteria}

Eligible staff were as follows: community-based (eg, nurses, occupational therapists, healthcare support workers, physiotherapists and associate practitioners in physical or mental healthcare); involved in screening and/or treatment activity relating to malnutrition; and expected to be in post for the duration of the study (12 months) either full time or part time. Those not involved in nutrition screening and treatment activity (eg, team administrators, other support staff) and staff not expecting to be in post for the duration of the study were ineligible. The 
research team sought to recruit the maximum number of willing participants of all roles and grades, due to lack of available demographic data to support a quota sample.

\section{Recruitment}

Prior to in-person invitation by the researcher (MB), potential participants $(n=89)$ were sent a Participant Information Sheet with contact details for the research team, circulated by team leads who received it via email. Potential participants were then approached at team meetings by the researcher (MB), at a time agreed with the team lead, where the study was introduced and participants' questions answered. Participants were informed of their right to withdraw at any stage without negative consequences, and without giving a reason. Participants then completed an agreement form (indicating consent to use of survey and interview audio data by the study team), a participant data form and the T0 NoMAD instrument (paper-based).

\section{Study procedures}

At T0, NoMAD questionnaires were completed at point of recruitment. At T1, questionnaires were circulated via team leads. Data collection for phase one occurred at baseline (T0-pre-implementation of procedure and training), and approximately 2-3 months following completion of training (T1). Each point involved completion of a 23-item questionnaire adapted from the NoMAD instrument (a measure of normalisation based on the NPT framework, see table 1), ${ }^{28} 32$ and a follow-up semistructured telephone interview (completed by a subsample of participants). Rationale for the methods and study design are now described in accordance with Good Reporting of a Mixed Methods Study criteria ${ }^{33}$ (see figure 1).

\section{NoMAD questionnaire}

NoMAD provides a measure of NPT construct in terms of their constituent components, indicating degree of success in relation to specific aspects of implementation (see table 1). This facilitates comparison across time points and between subgroups and provides a basis for exploring experiences of respondents in more detail through telephone interviews (described below). Each participant was given an envelope containing a questionnaire, which was completed and sealed before returning to the team lead (return envelopes did not contain identifiable information). At T0, participants completed and returned these directly to the researcher (MB). At T1, participants were informed by email/text message that questionnaires were available for completion; 2 weeks thereafter a reminder email/text message was sent, and completed questionnaires were then collected by a researcher $(\mathrm{MB})$ after a further week (3-week interval accommodated staff annual leave).

\section{Telephone interviews}

Following T0 NoMAD completion, a subsample of participants were invited to participate in a follow-up semistructured telephone interview. In addition to exploring
NoMAD responses for each of the NPT components, qualitative interviews offered several benefits. First, identification of factors not visible through NoMAD (eg, how implementation may affect local contexts, eg, within different teams ${ }^{34}$ ), allowing for iterative development of additional questions (to be added after the items adapted from NoMAD) at future observation points (ie, interviews at $\mathrm{T} 0$ generated questions which were added to the questionnaire at $\mathrm{T} 1$, which are reported in the findings section). Second, interviews offered opportunities to elaborate on responses to NoMAD. This was useful for exploring congruence between beliefs/attitudes and actions/experiences. Given that NPT focuses primarily on individual and collective action (ie, the work that people do as individuals and within collectives to enact and embed a new set of practices), semistructured interviewing offered an opportunity to ensure that this was explored effectively.

\section{Data collection, management and analysis \\ Data collection and storage}

Questionnaire responses were collected via paper instruments, and audio data from interviews were collected using digital dictaphones; both were stored electronically and securely on Bournemouth University (BU) servers, in password protected folders to which only the project team had access. For transcription, files were sent using a secure drop off-service, to a transcription service with which the study team had a confidentiality and non-disclosure agreement.

\section{Data analysis}

Results from NoMAD were analysed using descriptive and inferential (Wilcoxon rank-sum test for between-group differences in response, Wilcoxon signed-rank test for pre-post differences within groups) statistics using SPSS V.23 (threshold for statistical significance was defined at the 0.05 level).$^{35}$ NoMAD results contain no domain-specific scores, and only answers to individual questions were calculated. Mean scores with accompanying SD are here reported for Q4-23. The decision to report NoMAD results as means rather than medians was taken for two reasons. First, the mean value gives a more precise indication of the direction of response (eg, for a distribution of scores where mean $=2.5$ and median $=2$, the former provides meaningful additional detail indicating direction closer to neutral response than is visible from the median score). Second, reporting to one decimal place provides a more detailed basis for the colour gradient used to aid interpretation of results tables (ie, intensity of colour is linked to tendency towards the response, ie, is, strongly agree (blue), neither agree nor disagree (white), strongly disagree (yellow)). Neutral colours were chosen due to the mixed direction of NoMAD questions (ie, agreement with statements does not always indicate desirable response). Further exploration of methodological literature was undertaken to confirm appropriateness of this approach for analysis of likert-type data. ${ }^{36} 37$ 


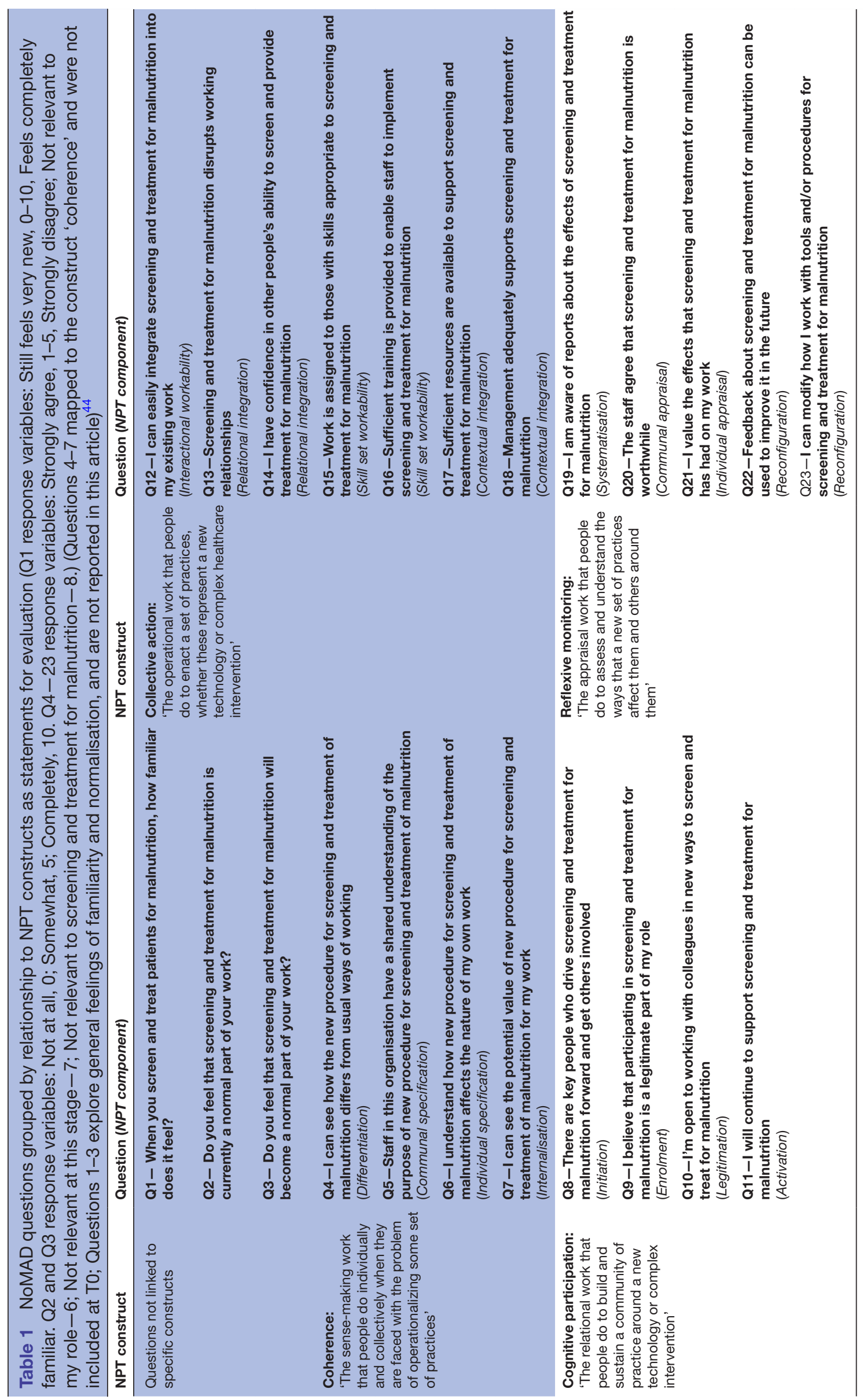




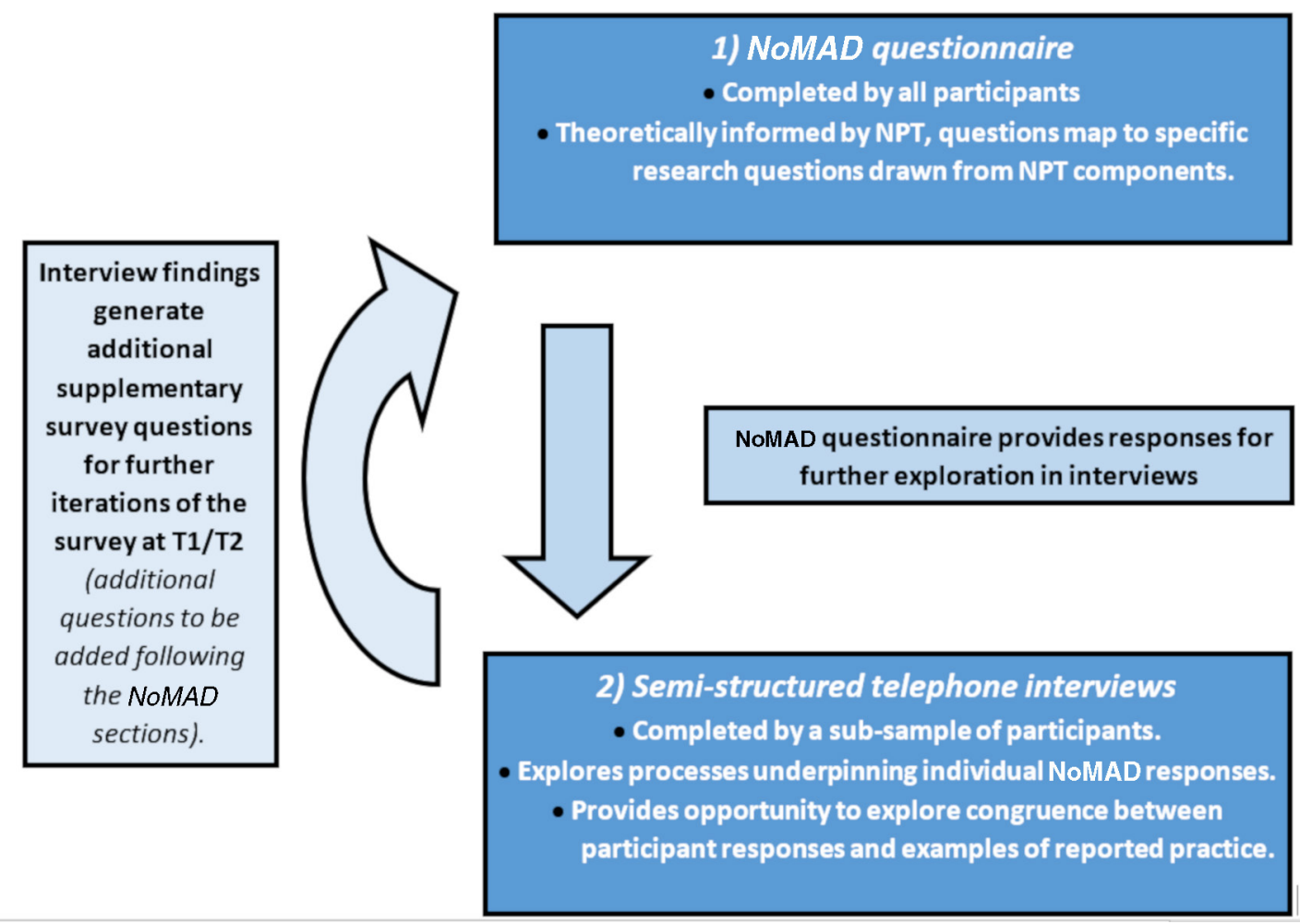

Figure 1 Relationship between Intergrated Community Team/Older People's Mental Health team (ICT/OPMH) participant questionnaire and semistructured telephone interview data. NPT, normalisation process theory.

Qualitative data were analysed through directed content analysis informed by NPT, using a constant comparative approach, performed using NVivo V.11 software. ${ }^{38} 39$ NVivo allows users to attach labels (or 'codes') to text, audio, video or image data, and facilitates data management through which directed content analysis can be conducted by a competent user. In this study, a list of codes was established based on NPT (see table 1) and used to identify relevant portions of audio and transcription data from interviews.

Interviews were performed by one researcher (MB), and audio data sent to an external transcription service immediately on completion (all interviews were returned within 14 days). On receipt of transcripts, data integrity checks were performed by one researcher (MB), which involved reading the transcript along with audio to ensure congruence between the two. This also served as a familiarisation procedure prior to initial directed content analysis, where initial themes relating to NPT components and linked questions within the NoMAD survey were identified by one researcher (MB). Emerging content of these themes was then discussed at group meetings with all co-authors (MB, JM, KW, KS and CRM), with the aim of agreeing relevance of material to individual codes (eg, whether an interview extract applied to a specific NPT construct, and/or whether it is relevant to other constructs). Following group discussion, amendments were made as necessary. This process repeated across three team meetings as interviews were completed (following the constant comparative approach), with themes agreed at the final meeting following completion of all interviews (a flowchart detailing this process is given in figure 2).

\section{Study sample}

Staff $(n=89)$ were approached at T0, of which 73 consented to participate. The recruitment rate at $\mathrm{T} 0$ was $79 \%$. The recruited sample T0 comprised 42 physical health (community) nurses, seven mental health nurses, 16 healthcare support workers, four occupational therapists, one physiotherapist and one other practitioner

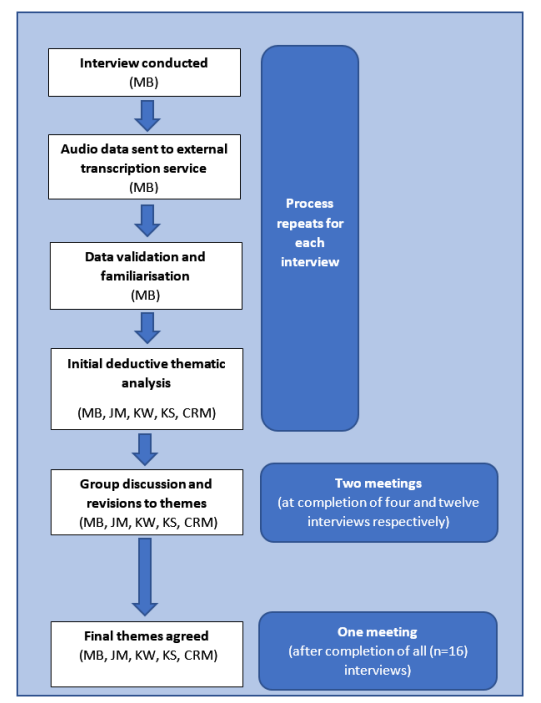

Figure 2 Process for deductive thematic analysis of interview data (responsible authors at each stage identified by initials). 
Table 2 Demographic characteristics of study sample

\begin{tabular}{lccc}
\hline Role & NoMAD T0 (n) & Interview T0 (n) & NoMAD T1 (n) \\
\hline Mental health nurse & 7 & 2 & 1 \\
Physical health (community) nurse & 42 & 13 & 22 \\
Occupational therapist & 4 & 1 & 4 \\
Healthcare support worker & 16 & 0 & 4 \\
Physiotherapist & 1 & 0 & 1 \\
Associate practitioner & 2 & 0 & 0 \\
Other (consultant-grade practitioner) & 1 & 0 & 0 \\
Total participants (all roles/bands) & 73 & 16 & 32
\end{tabular}

of consultant level (This participant's specific role has been anonymised.). Further details of the study sample are given in table 2. A subsample of 16 participants also completed semistructured telephone interviews following completion of NoMAD at T0 (see table 2; for a full description of approach process for interview, see online supplementary file 2). At T1, 32 participants completed follow-up NoMAD questionnaires (attrition rate $=56 \%$ ), 13 of which participated in the training while 19 did not. Of the 41 participants who did not complete T1, 12 participants (16\% of the T0 recruited sample) were identified as having left their teams, including four team leads representing a third of those included in the study $(n=12)$. Reasons for non-completion at T1 by the remaining 29 participants were not given. NoMAD results reported here reflect only those who completed at both T0 and T1 ( $\mathrm{n}=32$ participants).

\section{Patient and public involvement}

There was no patient or public involvement in the design or conduct of this study, which was a process evaluation of practice change and involved only staff.

\section{RESULTS}

\section{Baseline (TO)}

Staff already support nutrition screening and treatment activity, see its value and do not view it as disruptive to other work

T0 NoMAD responses indicate strong support for, and value placed on, nutrition screening and treatment activity. In all, 94\% $(n=30)$ of total participants $(n=32)$ strongly/agreed that staff see this activity as worthwhile (Q20, mean score=2.0, see table 3).97\% ( $\mathrm{n}=31)$ strongly/ agreed that screening and treatment of malnutrition was a legitimate part of their role $(Q 9$, mean score $=1.6$, see table 4$) .81 \%(n=26)$ strongly/agreed that they valued the effect that screening and treatment for malnutrition has had on their work $(Q 21$, mean score $=2.0$, table 3). $97 \%$ $(n=31)$ strongly/agreed that they were open to working with colleagues in new ways to support this work (Q10, mean score $=1.4$, table 4$) .97 \%(n=31)$ also strongly/ agreed that they would continue to support this work (Q11, mean score $=1.4$, table 4). This was reflected in responses of 14 participants to telephone interview (T1), all of which were compatible with openness to introducing new ways of working, though three also raised concerns with respect to the time/resource implications of implementation and embedding (see table 5).

Existing arrangements for nutrition screening and treatment could easily be integrated into their overall body of work, and were not seen to disrupt working relationships. $78 \%(n=25)$ of total respondents strongly/agreed that existing nutrition screening and treatment activity could easily be integrated into their overall body of work (Q12, mean score $=2.0$, see table 6 ). $79 \%$ strongly/disagreed that screening and treatment of malnutrition disrupts working relationships (Q13, mean score $=1.9$, see table 6 ). Six respondents from interviews described discussion of screening and treatment of malnutrition as a common feature of team meetings (see table 5).

Concerns exist as to wider organisational support for nutrition screening and treatment by community teams, as well as access to dietetic support

Uncertainty or doubt was expressed by many participants regarding logistical and organisational support for screening and treatment related activity. 59\% of respondents were uncertain (44\%) or strongly/disagreed $(15 \%)$ with the statement ' $[\mathrm{t}]$ here are key people who drive screening and treatment for malnutrition forward and get others involved' (Q8, mean score=2.9, see table 4). Of the 16 interview participants asked to about their response, 13 could not identify a key person. Of these 13, six highlighted absence of a 'key' or 'link' member of staff to provide advice, support and best practice updates (identified as being in place in other areas of practice, eg, infection control-see table 5).

In all, 16 interview participants were asked about dietetic referral in previous practice. Of these, two participants confirmed that they had been able to refer to a dietitian, the remainder $(n=13)$ had not referred in their current role. Of the 13 who had not referred: three stated that this should be possible in principle through the general practitioner; six further participants were unsure if or how this would be possible. Of total $(n=16)$ respondents, five stated explicitly that access to dietetic services in the community needed improvement (see table 5). 

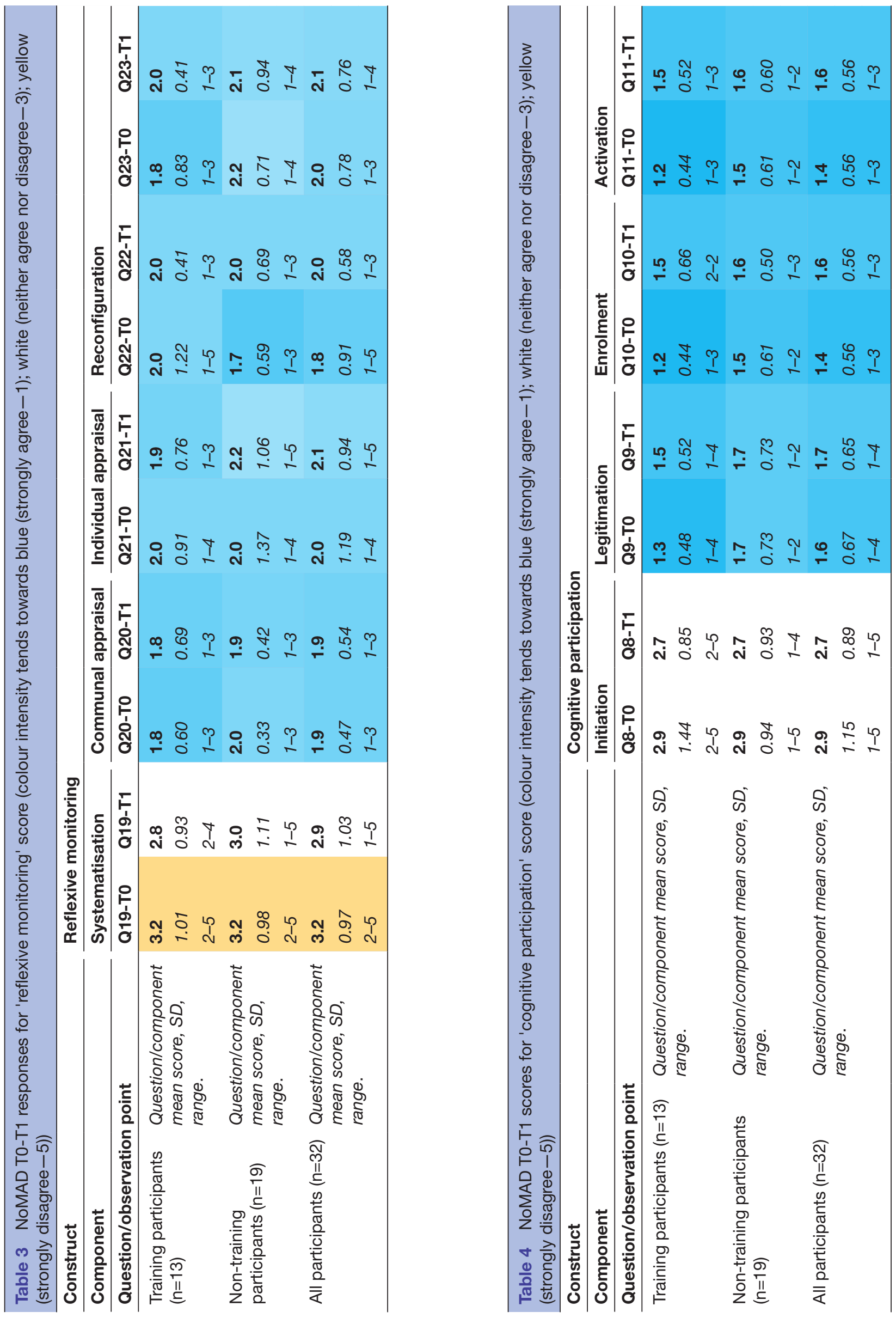
Table 5 Interview findings and illustrative quotes

\section{Finding}

Interview quote

Openness to introducing new ways of working (14 respondents); concerns (T)he thing that does concern me is the time to imbed the new practice because there regarding time/resource implications of trying to imbed the practice is really challenging when it's moving so fast and the work implementation and embedding (three respondents)

load is going through the roof; I think taking the time with the patient to be able to completely embed it is a challenge but I don't think, I think as a team, I've only been here a short while, but as a team they seem really keen to improve and implement anything that's new and that's better. (P00905, PHN)

Discussion of screening and treatment No it's never disruptive and it's never caused an issue for anyone, that's why I of malnutrition as a common feature of disagreed, we are quite a good stable team that get on well together and support each team meetings (six respondents) other when we are doing the work. (P00611, PHN)

$\begin{array}{ll}\begin{array}{l}\text { Absence of a 'key' or 'link' member of } \\ \text { staff to provide advice, support and } \\ \text { best practice updates (six respondents) }\end{array} & \begin{array}{l}\text { It whould be a preference definitely to implement some kind of key worker strategy } \\ \text { whink yeah with regards to that yes it definitely would be a more effective way of } \\ \text { working if that was possible so that would be something good to be implemented I } \\ \text { guess. (P00614, PHN) }\end{array} \\ \begin{array}{ll}\text { Access to dietetic services in the } \\ \text { community in need of improvement } \\ \text { (five respondents) }\end{array} & \begin{array}{l}\text { I mean my only concern is, my understanding is there is not many community dietitians } \\ \text { you know so it's just sort of getting advice, obviously we will refer to the GP but it's not } \\ \text { often we get input from dietitians themselves. We've sort of got basic guidelines on } \\ \text { how to go through, so to have some more input from dietitians would be really good, } \\ \text { really useful. (P00210, PHN) }\end{array} \\ \end{array}$

In total, $56 \%(\mathrm{n}=18)$ were uncertain or strongly/ disagreed with the statement 'Work is assigned to those with skills appropriate to screening and treatment for malnutrition' (Q15, mean score $=2.8$, see table 6 ). $62 \%$ $(n=12)$ strongly/disagreed or were uncertain in relation to the statement 'Sufficient training is provided to enable staff to implement screening and treatment for malnutrition' (Q16, mean score $=3.1$, see table 6). 59\% were uncertain $(40 \%)$ or strongly/disagreed $(19 \%)$ that 'Sufficient resources are available to support screening and treatment for malnutrition' (Q17, mean score $=2.9$, table 6$) .66 \% \quad(n=21)$ were uncertain or strongly/ disagreed that 'Management adequately supports screening and treatment for malnutrition' (Q18, mean score $=2.5$, table 6 ).

\section{Training outcomes}

In all, 126 staff members within the implementation area completed training, representing $56 \%$ of full-time staff $(n=223)$ at initiation of training $(23 \% \quad(n=30)$ of those completing were INSCCOPe participants). $40 \%(n=29)$ of INSCCOPe participants $(n=73)$ completed training; $60 \%$ did not (see online supplementary additional file 3 , tables 1 and 2). Pre-post knowledge check scores indicated that training had been effective in raising average knowledge check score for all participants from 54\% immediately prior to training to $68 \%$ for immediately post-training (see online supplementary additional file 3 , table 3 ). All role groups saw an increase in average scores, the largest (23\%) for healthcare support workers, while the smallest (7\%) was for occupational therapists and associate practitioners (see online supplementary additional file 3, table 3).

\section{T1 results}

Results for NoMAD responses within the 'coherence' construct (Q4-7)

Four questions (Q4-7) mapping to 'coherence' and its components were added to NoMAD instrument at T1 (see table 7). For all participants completing T1, 46\% $(n=15)$ disagreed or were uncertain in response to the statement (Q4): 'I can see how the new procedure for screening and treatment of malnutrition differs from usual ways of working' (mean score $=2.7$, see table 7 ). The same responses represented $38 \%(n=5)$ of training participants (mean score=2.5) and 52\% $(\mathrm{n}=10)$ of non-training participants (mean score $=2.7$, see table 7 ). This indicates that for those who both did and did not complete the training, differentiation of the new procedure introduced through training for existing practice requires further attention.

In the $\mathrm{T} 1$ all participant group, $41 \%(\mathrm{n}=13)$ disagreed or were uncertain regarding the statement (Q5): 'Staff in this organisation have a shared understanding of the purpose of new procedure for screening and treatment of malnutrition' (mean score $=2.7$, see table 7 ). Responses of this type represented $38 \%(n=5)$ in the training participant group (mean score $=2.5$, and $42 \%$ $(n=9)$ of the non-training group (mean score $=2.9$, see table 7). Results indicate a large proportion in both subgroups for whom shared understanding (communal specification) of the procedure remains vague.

In total, $25 \%(\mathrm{n}=8)$ of the all participant group were uncertain of disagreed with the statement $(\mathrm{Q} 6)$ : 'I understand how the new procedure for screening and treatment of malnutrition affects the nature of my own work' (mean score $=2.4$, see table 7 ). Respondents 


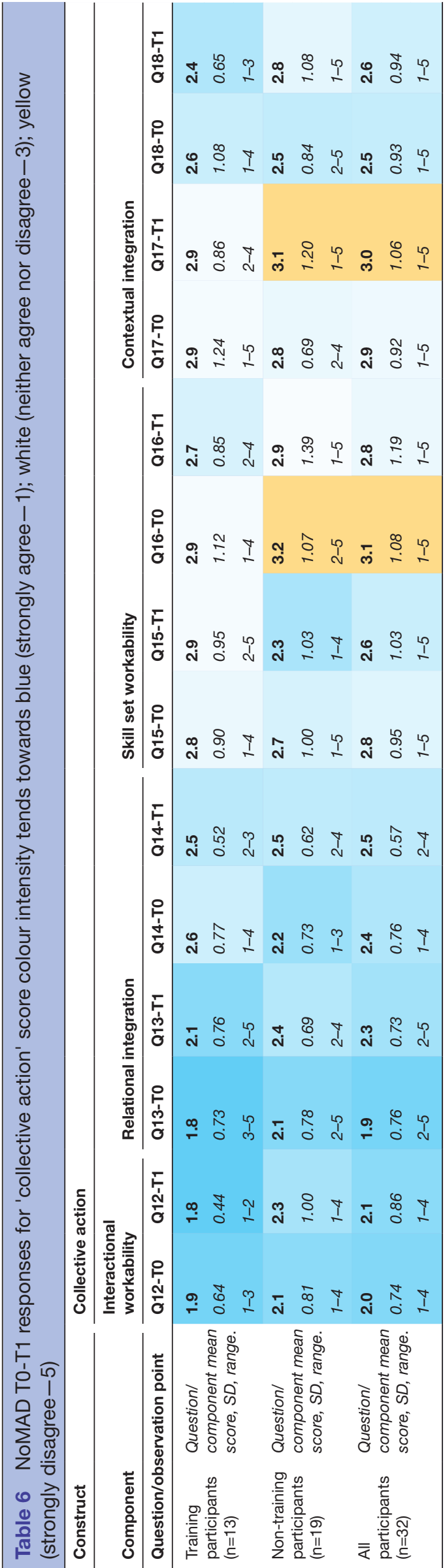

providing such answers represented only one response in the training participant subgroup (mean score $=2.0$ ), with seven such responses representing $37 \%$ of training non-training group (mean score $=2.7$, see table 7 ). Here, results indicate a potential difference in how well participants in respective subgroups understood the new procedure in terms of their own practice (individual specification), though difference between observations did not reach statistical significance $(p=0.06$, see online supplementary additional file 4, table 1). Comparing this with results from Q5, results indicate a greater effect of training on understanding implications for individual working compared with team working.

In total, $75 \%(\mathrm{n}=24)$ of all participants strongly/ agreed with the statement $(\mathrm{Q} 7)$ : 'I can see the potential value of the new procedure for screening and treatment of malnutrition for my work' (mean score $=2.2$, see table 7$) .92 \%(\mathrm{n}=12)$ of the training participant group (mean score $=1.7)$ and $37 \%(\mathrm{n}=7)$ of the non-training participant group (mean score $=2.6$, see table 7 ) gave such responses. This difference between subgroups was significant $(p=0.01$, see online supplementary additional file 4, table 1 ) and indicates a potential impact of training on value placed on the new procedure.

\section{Changes in NoMAD response (T0-T1)}

Wilcoxon signed-rank tests were used to investigate differences between responses to Q8-23 for all participants $(n=32)$, training participants $(n=13)$ and non-training participants $(n=19)$, respectively. For all participants, only Q13 saw a significant change from T0 (mean score $=1.9)$ to T1 (mean score $=2.3$, see table 6 ), which involved a shift towards uncertainty or disagreement with the statement 'Screening and treatment for malnutrition disrupts working relationships' $(\mathrm{T}=32.00$, $\mathrm{r}=-0.29, \mathrm{p}=0.02$; see online supplementary additional file 4, table 2). This indicates small-to-moderate effect on responses during the period in which the training took place. No other significant changes were observed (see online supplementary additional file 4, tables 2-4).

\section{Differences between sub-group responses ( $\mathrm{T} 0$ and $\mathrm{T} 1$ )}

A significant difference was observed for $\mathrm{Q} 7-\mathrm{T} 1$ ( $\mathrm{W}=124$, $\mathrm{r}=-0.43, \mathrm{p}=0.01$ ). No significant differences were found for any other questions at either time points (see online supplementary additional file 4 , tables $1,5-7$ ).

\section{Dietetic questions}

Interview responses at $\mathrm{T} 0$ indicated access to dietetic services was a significant concern for many participants. Additional questions regarding availability and adequacy of dietetic services were appended to questionnaires at T1. Overall, results show that $30 \%-90 \%$ of all participants had concerns about or were uncertain in relation to, all aspects of dietetic service explored by question statements (see table 8). Proportions of responses were similar for both training and non-training participants in most areas (A1-2, A4-6), and Wilcoxon rank-sum test results 
Table 7 NoMAD T1 mean scores for 'coherence' (score colour intensity tends towards blue (strongly agree-1); white (neither agree nor disagree-3); yellow (strongly disagree-5))

\begin{tabular}{|c|c|c|c|c|c|}
\hline \multicolumn{2}{|l|}{ Construct } & \multicolumn{4}{|l|}{ Coherence } \\
\hline \multicolumn{2}{|l|}{ Component } & Differentiation & $\begin{array}{l}\text { Communal } \\
\text { specification }\end{array}$ & $\begin{array}{l}\text { Individual } \\
\text { specification }\end{array}$ & Internalisation \\
\hline \multicolumn{2}{|c|}{ Question/observation point } & Q4 & Q5 & Q6 & Q7 \\
\hline \multirow{3}{*}{$\begin{array}{l}\text { Training participants } \\
(n=13)\end{array}$} & \multirow{3}{*}{$\begin{array}{l}\text { Question/ } \\
\text { component mean } \\
\text { score, SD, range. }\end{array}$} & 2.5 & 2.5 & 2.0 & 1.7 \\
\hline & & 0.66 & 0.66 & 0.41 & 0.49 \\
\hline & & $2-4$ & $2-4$ & $1-3$ & $1-2$ \\
\hline \multirow{3}{*}{$\begin{array}{l}\text { Non-training } \\
\text { participants }(n=19)\end{array}$} & \multirow{3}{*}{$\begin{array}{l}\text { Question/ } \\
\text { component mean } \\
\text { score, SD, range. }\end{array}$} & 2.7 & 2.9 & 2.7 & 2.6 \\
\hline & & 1.59 & 1.50 & 1.63 & 1.59 \\
\hline & & $1-4$ & $1-5$ & $1-5$ & $1-5$ \\
\hline \multirow{3}{*}{$\begin{array}{l}\text { All participants } \\
(n=32)\end{array}$} & \multirow{3}{*}{$\begin{array}{l}\text { Question/ } \\
\text { component mean } \\
\text { score, } S D \text {, range. }\end{array}$} & 2.6 & 2.7 & 2.4 & 2.2 \\
\hline & & 1.31 & 1.23 & 1.33 & 1.37 \\
\hline & & $1-4$ & $1-5$ & $1-5$ & $1-5$ \\
\hline
\end{tabular}

Table 8 Results as percentages for responses to additional dietetic questions at T1

\begin{tabular}{|c|c|c|c|}
\hline & Training group & $\%$ Strongly/agree & $\%$ Strongly/disagree or uncertain \\
\hline \multirow{3}{*}{$\begin{array}{l}\text { A1- I know where to get } \\
\text { specialist support and advice } \\
\text { on treatment for malnutrition if I } \\
\text { need it }\end{array}$} & Non-training participants $(n=19)$ & 0.47 & 0.47 \\
\hline & Training participants $(n=13)$ & 0.54 & 0.38 \\
\hline & All $(n=32)$ & 0.50 & 0.44 \\
\hline \multirow{3}{*}{$\begin{array}{l}\text { A2-I have sufficient access to } \\
\text { patient information resources } \\
\text { relating to malnutrition }\end{array}$} & Non-training participants $(n=19)$ & 0.47 & 0.47 \\
\hline & Training participants $(n=13)$ & 0.69 & 0.31 \\
\hline & All $(n=32)$ & 0.56 & 0.41 \\
\hline \multirow{3}{*}{$\begin{array}{l}\text { A3-Patient information } \\
\text { resources relating to malnutrition } \\
\text { are useful and effective }\end{array}$} & Non-training participants $(n=19)$ & 0.32 & 0.63 \\
\hline & Training participants $(n=13)$ & 0.69 & 0.31 \\
\hline & All $(n=32)$ & 0.47 & 0.50 \\
\hline \multirow{3}{*}{$\begin{array}{l}\text { A4-My team has access to a } \\
\text { dietitian if a patient requires it }\end{array}$} & Non-training participants $(n=19)$ & 0.32 & 0.63 \\
\hline & Training participants $(n=13)$ & 0.38 & 0.54 \\
\hline & All $(n=32)$ & 0.34 & 0.59 \\
\hline \multirow{3}{*}{$\begin{array}{l}\text { A5- } 1 \text { know the procedure for } \\
\text { referring a patient to a dietitian if } \\
\text { required }\end{array}$} & Non-training participants $(n=19)$ & 0.42 & 0.53 \\
\hline & Training participants $(n=13)$ & 0.46 & 0.54 \\
\hline & All $(n=32)$ & 0.44 & 0.53 \\
\hline \multirow{3}{*}{$\begin{array}{l}\text { A6-Availability of dietitians is } \\
\text { sufficient to meet the needs of } \\
\text { our patients }\end{array}$} & Non-training participants $(n=19)$ & 0.05 & 0.89 \\
\hline & Training participants $(n=13)$ & 0.23 & 0.77 \\
\hline & All $(n=32)$ & 0.13 & 0.84 \\
\hline \multirow{3}{*}{$\begin{array}{l}\text { A7-Current state of } \\
\text { malnutrition screening is } \\
\text { sufficient to meet the needs of } \\
\text { our patients }\end{array}$} & Non-training participants $(n=19)$ & 0.58 & 0.37 \\
\hline & Training participants $(n=13)$ & 0.38 & 0.54 \\
\hline & All $(n=32)$ & 0.50 & 0.44 \\
\hline \multirow{3}{*}{$\begin{array}{l}\text { A8-Current arrangements for } \\
\text { treatment of malnutrition are } \\
\text { sufficient to meet the needs of } \\
\text { our patients }\end{array}$} & Non-training participants $(n=19)$ & 0.21 & 0.74 \\
\hline & Training participants $(n=13)$ & 0.54 & 0.38 \\
\hline & All $(n=32)$ & 0.34 & 0.59 \\
\hline
\end{tabular}


between subgroup response to each question showed no statistically significant differences (see online supplementary additional file 4, table 5). These results echo those indicated by telephone interviews, that many participants appear to have doubts regarding adequacy of dietetic services in relation to procedure, support, and resource allocation.

\section{DISCUSSION}

The aim of the INSCCOPe study was to undertake a process evaluation of implementation of the screening procedure and its associated training, and identify factors promoting or inhibiting embedding of nutritional screening in routine care. Study findings indicate that staff value nutrition screening and treatment activity and are open to new ways of working (indicating favourable conditions relating to the Internalisation and Relational integration components of NPT). In addition, training is effective in improving knowledge of the new procedure. However, participant responses highlighted lack of institutional support for nutrition screening (Contextual integration), as well as absence of a 'key' person to support and drive forward service development (Initiation), indicating that significant barriers to implementation remain. Implications of these findings and recommendations for addressing barriers are discussed, in addition to wider implications for implementation of service developments in community settings.

NoMAD responses mapping to Cognitive participation indicate conditions conducive to building and sustaining a community of practice around nutrition screening and treatment. Findings (T0 and T1) indicate that staff view such work as a legitimate part of their role (Q9, Enrol$m e n t$ ), are open to working with colleagues in new ways in relation to it (Q10, Legitimation) and will continue to support further development in this area (Q11, Activation). In addition, responses (both $\mathrm{T} 0$ and $\mathrm{T} 1$ ) indicate that both baseline arrangements for nutrition screening and treatment, as well as the new procedure, and can be easily integrated into existing work (Q12, Interactional workability). Between $\mathrm{T} 0$ and $\mathrm{T} 1$, there was a shift in average scores towards 'neither agree nor disagree' and away from 'strongly agree' in relation to perceptions of disruptiveness of nutrition screening and treatment for working relationships (Q13, Relational integration). This shift was significant for non-training participants $(\mathrm{p}=0.02)$, and was observed but did not reach statistical significance for training participants $(\mathrm{p}=0.07)$, indicating that implementation may have had some effect on staff perceptions of effect of nutrition screening and treatment on working relationships. However, mean scores for both groups at T1 (2.1 for training, 2.4 for non-training) indicate that many participants still see this activity as disruptive to working relationships.

Results indicate several challenges to current implementation design: first, non-completion of training (44\% of total staff $(n=223)$ did not complete). Concerns regarding time and resource constraints for nutrition screening and treatment activity (see Q17, table 6; and table 5) were indicated in both NoMAD (T0 \& T1) and interview responses. Furthermore, study team experiences in recruitment to telephone interview indicated a number of participants who declined to participate, or agreed and then were forced to withdraw, in both cases due to changes in workload (see online supplementary additional file 2). These observations indicate changeable demands that characterise community team working environments, and affect attendance at in-person training sessions that are non-mandatory. Second, working environments also include significant attrition of key staff; 12 participants left post between $\mathrm{T} 0$ and $\mathrm{T} 1$, of which four were team leads. This risks reduction in numbers trained in the new procedure, as well as key people able to monitor compliance and provide appropriate support (ie, team leads). Third, effect of staff attrition on overall procedure compliance may be compounded by lack of monitoring of training (ie, while pre-post knowledge checks were taken, no procedures for monitoring ongoing compliance currently exist). Fourth, concerns about institutional support for nutrition screening and treatment activity (as indicated through interviews and responses to dietetic survey questions) persisted after introduction of the procedure through training. Further attention to Contextual integration processes is necessary, specifically support provided by management for nutrition screening and treatment activity, and how this is made available to community teams.

In response, we propose two main changes to implementation design. First, appointment of a key person for the new procedure, with specialist nutritional expertise and remit to monitor training completion rates and procedure compliance; disseminate practice updates; provide advice and support for nutrition screening and treatment. This addresses a suggestion by several interview participants, who cited benefits of this role in other areas such as wound care, as well as a gap indicated by uncertain survey responses (NoMAD Q8-see table 4). The value of such a role in implementing new nutritional care procedures has also been demonstrated in secondary care settings in helping staff understand new nutritional procedures (coherence) and work through changes to their existing practices and relationships (cognitive participation). ${ }^{11}{ }^{34}$ Updates on compliance, training and resource needs would be provided to senior managers at regular intervals, moving from a single-point intervention at the level of Healthcare Professionals (HCPs) through training, to one that links monitoring and resource allocation directly to those with responsibility to ensure successful implementation of the new procedure (thus creating an organisational feedback loop to promote sustainability and embedding in management practice). Second, training design needs to be adaptable to cope with changeable working patterns, organisational and resource support challenges, and staff turnover that restricted training participation and left those 
who did complete training vulnerable to attrition. One option might be to make training mandatory for all staff; however, the procedure development and delivery team indicated that this would not be possible currently. We therefore recommend that training is delivered through existing organisational e-learning systems, rather than in person. This change is intended to deliver several improvements. First, widening of scope for participation in changeable working conditions, thereby increasing resistance of implementation to organisation turbulence. Second, connecting training in the new procedure with existing nutritional e-learning resources on screening of malnutrition (see online supplementary additional file 1 , Section 6.1), thereby increasing coherence (specifically differentiation, individual and communal specification) of the new procedure in terms of its relation to existing nutritional working practices. Third, location of both new and existing training components within e-learning offers the potential to reduce costs associated both with training provision, and resources needed for monitoring and support of procedure training and compliance.

\section{Implications and future research directions}

While barriers here identified relate to specific processes within the study field, they are relevant to implementation in general such as enabling participation (enrolment); responding to workforce turbulence (communal appraisal; reconfiguration); monitoring of compliance (systematisation) and ensuring adequate provision of resource (contextual integration). These components fall within the 'collective action' and 'reflexive monitoring' domains of NPT, indicating importance of these domains for successful implementation. These observations echo those of Johnson \& May's ${ }^{40}$ theory-led overview of systematic reviews of interventions to promote professional practice change, insofar as positive attitudes of staff were outweighed by lack of engagement with collective action. ${ }^{40}$ The present study highlights the importance of key people as 'pumps' to drive and sustain organisational behaviour loops, adding to extant literature emphasising importance of individuals with resource, authority and legitimacy (both personal and institutional) to drive forward new developments in healthcare. ${ }^{11} 27344142$ In addition, it indicates the importance of designing intervention objects that are resilient to organisational turbulence. Many healthcare interventions take place in complex settings wherein emergent and contextual factors can modify the conditions of implementation. Providing organisational 'closure' through monitoring and support of a key person is important in mitigating these effects; however, objects of interventions (eg, procedures, training seminars, technologies, etc) are important in this process. In the INSCCOPe study, the proposed move from in-person to online delivery of the training was an example of how an intervention object may be redesigned in response to turbulence encountered within the field of implementation.

These findings are interdependent; appropriate design choices for objects can only be expected to have effects if participants are directed to use them in some way, which typically involves organisational work of key people. In their evaluation of an intervention to support carers of stroke survivors, Clarke $e t a \hat{l}^{34}$ observed that participants unable to attend training did not make use of replacement resources (a DVD) because they were not directed to do so. ${ }^{34}$ The observations from the present study add to extant literature indicating importance of contextual factors (ie, turbulence) as well as creating practical (rather than simply attitudinal) conditions for professional behaviour change, as key determinants in success (or failure) of service development initiatives.

Turning specifically to implementation in community settings, further empirical study of involvement of key decision-makers at higher levels of governance is an important focus. In this study, a majority $(66 \%)$ of NoMAD respondents at T0 strongly/disagreed with the statement 'Management adequately supports screening and treatment for malnutrition' (Q18, see table 6), a finding which persisted at T1. Previous work in other settings by Bamford et $a l^{12}$ has also highlighted the importance of senior management support for implementation of nutritional care interventions within residential care homes. ${ }^{12}$ While studies such as INSCCOPe contribute to understanding of implementation for staff and teams, it is also necessary to explore further how NPT mechanisms operate among those funding and overseeing services at a strategic level.

\section{Practical issues in the INSCCOPe study: work necessary to secure and maintain participation}

Considerable work was necessary to recruit and conduct interviews with participants (see online supplementary additional file 2), and to obtain NoMAD responses at T1 (where questionnaires were left with team leads for circulation and completion, instead of completing in the presence of a researcher as occurred during recruitment at T0). In all, 116 telephone calls were made to secure 16 interviews, with seven participants requiring one or more rearrangements of their scheduled time, and four cancelling after initial agreement. In almost all cases where contact was made, inability to participate or need for rescheduling was attributed to volume and changeability of workload. We recommend that future studies involving community teams be aware of this as a necessary condition of research in this field, and that questionnaire instruments are completed during in-person visits by a researcher where possible.

\section{Limitations of the study}

The study protocol stated that a quota sample would be used, derived from 'data on composition of target population by role (eg, community nurse, physiotherapist) and NHS Agenda for Change (AfC) band (the current grading system for staff seniority within in the target population) (which would be) provided by the trust'. ${ }^{4}$ Unfortunately, these data were not made available to the INSCCOPe team, and as such we adopted a strategy of 
maximum recruitment within each team. This limited our reporting of relationships between sample and target populations with respect to these characteristics. While 72 participants were originally recruited at $\mathrm{T} 0,32$ went on to complete NoMAD at T1. While 12 participants were identified as having left their teams $(16 \%$ of the T0 sample), reasons for non-completion were unavailable for 29 further participants. This reduction indicates vulnerability of prospective studies in complex healthcare environments to participant attrition, a factor in which may have been that questionnaires at $\mathrm{T} 1$ were cascaded to participants at team meetings via team leads, whereas at T0 they were completed at the point of recruitment in the presence of a researcher. For data collection at T2, the INSCCOPe team will attend team meetings in person to administer instruments, to avoid potential risks of further attrition (eg, questionnaires getting lost due to changeable working conditions of team leads). Both survey and interview contained questions relying on participant recollection of events over varying periods of time, and as such recall and response bias may be present. Finally, there are indications of differences between training and non-training participants in relation to implementation indicators, as well as differences between $\mathrm{T} 0$ and $\mathrm{T} 1$, that did not reach statistical significance but may warrant further exploration. The aim of this article was to present results from phase one of implementation, to identify factors promoting or inhibiting its implementation and indicate how these have informed recommendations for further development. Further discussion is therefore beyond the scope of the current paper; however, we intend to explore these issues further in a future article reporting results from phase two of implementation, wherein we can explore them in relation to the effect of changes recommended here.

\section{CONCLUSION}

We have presented a prospective process evaluation, exploring initial implementation of a new procedure for screening and treatment of malnutrition in community settings. Guided by NPT, we have explored factors promoting implementation and embedding of the new procedure (ie, staff understanding of the effectiveness, legitimacy and appropriateness of the intervention). In addition, we have highlighted aspects of the implementation field presenting challenges to implementation (ie, non-completion of training, staff attrition, lack of ongoing monitoring for procedure compliance, concerns around institutional support for nutrition screening and treatment activity). In so doing, we have highlighted some generic aspects of implementation relevant to service development in community settings and proposed two specific areas of attention for those designing such interventions. These findings add to the wider knowledge base on implementation and embedding by supporting and extending observations regarding the importance of collective action and reflexive monitoring mechanisms.
Author affiliations

${ }^{1}$ School of Health Sciences, University of Southampton, Southampton, UK ${ }^{2}$ Faculty of Health \& Social Sciences, Bournemouth University, Bournemouth, UK

${ }^{3}$ Southern Health NHS Foundation Trust, Southampton, UK

${ }^{4}$ Wessex Academic Health Science Network (AHSN), Southampton, UK

${ }^{5}$ Faculty of Epidemiology and Population Health, London School of Hygiene and Tropical Medicine, London, UK

${ }^{6}$ Department of Human Sciences \& Public Health, Bournemouth University, Bournemouth, UK

Acknowledgements The study team would like to acknowledge the support of the Burdett Trust for Nursing, and staff within Southern Health NHS Foundation Trust for their help and support in the development of this study.

Contributors JM, KW and KS devised the project (for which CRM and AA also provided advice). JM obtained funding at the host institution, Bournemouth University. JM managed the study as chief investigator. MB was primarily responsible for study design, protocol, data collection and analysis with input from $\mathrm{JM}, \mathrm{KW}, \mathrm{KS}, \mathrm{AA}$ and CRM. All authors contributed significant revisions to drafts of the manuscript, and have read and approved the final manuscript.

Funding The project is funded by The Burdett Trust for Nursing.

Competing interests None declared.

Patient consent for publication Not required.

Ethics approval Ethical approval for the study has been granted through institutional ethical review (Bournemouth University); NHS Heath Research Authority approval (IRAS ID - 223214) was granted on 05/04/2017. NHS Research Ethics committee approval was not required for this study, as it involves only staff.

Provenance and peer review Not commissioned; externally peer reviewed.

Data availability statement № data are available.

Open access This is an open access article distributed in accordance with the Creative Commons Attribution Non Commercial (CC BY-NC 4.0) license, which permits others to distribute, remix, adapt, build upon this work non-commercially, and license their derivative works on different terms, provided the original work is properly cited, appropriate credit is given, any changes made indicated, and the use is non-commercial. See: http://creativecommons.org/licenses/by-nc/4.0/.

\section{REFERENCES}

1. Craig P, Dieppe P, Macintyre S, et al. Developing and evaluating complex interventions: new guidance 2007.

2. May CR, Johnson M, Finch T. Implementation, context and complexity. Implement Sci 2016;11.

3. Greenhalgh T. How to Implement Evidence-Based Healthcare. Wiley, 2017. Available: https://books.google.co.uk/books?id= ySgnDwAAQBAJ

4. Moore GF, Audrey S, Barker M, et al. Process evaluation of complex interventions: medical Research Council guidance. BMJ 2015;350.

5. Community nursing: transforming health care community nursing: transforming health care. London, UK, 2011. Available: https://www. rcn.org.uk/-/media/royal-college-of-nursing/documents/publications/ 2011/november/pub-004165.pdf

6. Edwards N. Community services: How they can transform care. King's Fund 2014:1-24. Available: http://www.kingsfund.org.uk/ blog/2014/02/transforming-community-services-learning-previousmistakes

7. Todorovic V, Russell C, Elia M. The 'MUST' explanatory booklet, 2011. Available: http://www.bapen.org.uk/pdfs/must/must_explan. pdf

8. NICE. Nutrition support for adults: oral nutrition support, enteral tube feeding and parenteral nutrition. London, UK, 2006. Available: http:// nice.org.uk/guidance/cg32

9. NICE. Nutrition support in adults. London, UK, 2007. Available: http://www.nice.org.uk/nicemedia/live/10978/29978/29978.pdf\% 5Cnpapers3://publication/uuid/48F2C672-83ED-4CAB-9BDCBB22A7C7D3A1

10. Elia M. The cost of malnutrition in England and potential cost savings from nutritional interventions (full report) a report on the cost of disease-related malnutrition in support in adults 2015.

11. Johnson MJ, Leaf AA, Pearson F, et al. Successfully implementing and embedding guidelines to improve the nutrition and growth of preterm infants in neonatal intensive care: a prospective interventional study. BMJ Open 2017;7:e017727. 
12. Bamford C, Heaven B, May C, et al. Implementing nutrition guidelines for older people in residential care homes: a qualitative study using normalization process theory. Implement Sci 2012;7.

13. Brotherton A, Simmonds N, Stroud M. Malnutrition Matters - Meeting Quality Standards in Nutritional Care, 2010. Available: http://www. bapen.org.uk/pdfs/toolkit-for-commissioners.pdf

14. WHO. What is malnutrition? 2016. Available: http://www.who.int/ features/qa/malnutrition/en/ [Accessed 29 Sep 2017].

15. Elia M. The 'MUST' Report - Nutritional screening of adults: a multidisciplinary responsibility. Warminster, UK, 2003. Available: https://www.bapen.org.uk/pdfs/must/must-report.pdf

16. Elia M, Russell C. Combating malnutrition: recommendations for action, 2009. Available: https://www.bapen.org.uk/pdfs/reports/ advisory_group_report.pdf

17. Russell C, Elia M. Screening for malnutrition in sheltered housing. A report from BAPEN with the group on nutrition in sheltered housing (GNASH), 2009. Available: https://www.bapen.org.uk/pdfs/nsw/ gnash exec summary09.pdf

18. Wilson L. State of the Nation - Older People and Malnutrition in the UK today. London, UK, 2017. Available: http://www.malnutritiontask force.org.uk/wp-content/uploads/2017/10/AW-5625-Age-UK-MTF_ Report.pdf

19. Edington J, Barnes R, Bryan F, et al. A prospective randomised controlled trial of nutritional supplementation in malnourished elderly in the community: clinical and health economic outcomes. Clin Nutr 2004:23:195-204

20. Wilson L, Health RP. A review and summary of the impact of malnutrition in older people and the reported costs and benefits of interventions, 2013. Available: http://www.malnutritiontaskforce.org. uk/wp-content/uploads/2014/11/A-review-and-summary-of-theimpact-of-malnutrition-in-older-people-and-the-reported-costs-andbenefits-of-interventions.pdf

21. Hamirudin $\mathrm{AH}$, Charlton $\mathrm{K}$, Walton $\mathrm{K}$. Outcomes related to nutrition screening in community living older adults: a systematic literature review. Arch Gerontol Geriatr 2016;62:9-25.

22. Green SM, James EP, Latter S, et al. Barriers and facilitators to screening for malnutrition by community nurses: a qualitative study. $J$ Hum Nutr Diet 2014;27:88-95.

23. Hamirudin $\mathrm{AH}$, Charlton $\mathrm{K}$, Walton $\mathrm{K}$, et al. Feasibility of implementing routine nutritional screening for older adults in Australian general practices: a mixed-methods study. BMC Fam Pract 2014;15:186.

24. Wessex Academic Health Sciences Network (AHSN). Older People's Essential Nutrition (OPEN) Eastleigh Project, 2016. Available: http:// wessexahsn.org.uk/projects/60/older-people-s-essential-nutritionopen-eastleigh [Accessed 29 Sep 2017].

25. May C, Finch T. Implementing, embedding, and integrating practices: an outline of normalization process theory. Sociology 2009;43:535-54.

26. May CR, Cummings A, Girling $M$, et al. Using normalization process theory in feasibility studies and process evaluations of complex healthcare interventions: a systematic review. Implement Sci 2018;13.

27. Westbury JA, Johnson MJ, Pond JP, et al. Developing the role of the nurse as a link advisor for research and a champion for nutrition in the neonatal intensive care unit. J Neonatal Nurs 2013;19:198-205.
28. Finch TL, Rapley T, Girling M, et al. Improving the normalization of complex interventions: measure development based on normalization process theory (NoMAD): study protocol. Implement Sci 2013;8.

29. Finch TL, Girling M, May CR, et al. NoMAD: implementation measure based on normalization process theory, 2015. Available: http://www.normalizationprocess.org/resources/ [Accessed 21 Aug 2017]

30. Lund S, Richardson A, May C. Barriers to advance care planning at the end of life: an explanatory systematic review of implementation studies. PLoS One 2015;10:e0116629.

31. Pope C, Halford S, Turnbull J, et al. Using computer decision support systems in NHS emergency and urgent care: ethnographic study using normalisation process theory. BMC Health Serv Res 2013;13:111.

32. Finch TL, Girling M, May CR, et al. Improving the normalization of complex interventions: part 2 - validation of the NoMAD instrument for assessing implementation work based on normalization process theory (NPT). BMC Med Res Methodol 2018;18.

33. O'cathain A, Murphy E, Nicholl J. The quality of mixed methods studies in health services research. $J$ Health Serv Res Policy 2008;13:92-8.

34. Clarke DJ, Godfrey M, Hawkins R, et al. Implementing a training intervention to support caregivers after stroke: a process evaluation examining the initiation and embedding of programme change. Implement Sci 2013;8.

35. Field A. Discovering Statistics Using IBM SPSS Statistics. SAGE Publications, 2013. Available: https://books.google.co.uk/books?id= srb0a9fmMEoC

36. Norman G. Likert scales, levels of measurement and the "laws" of statistics. Adv Health Sci Educ Theory Pract 2010;15:625-32.

37. Sullivan GM, Artino AR. Analyzing and interpreting data from likerttype scales. J Grad Med Educ 2013;5:541-2.

38. Mason J. Qualitative researching. SAGE Publications, 2002.

39. Corbin J, Strauss A. Basics of Qualitative Research: Techniques and Procedures for Developing Grounded Theory. SAGE Publications, 2014. Available: https://books.google.co.uk/books?id= hZ6kBQAAQBAJ

40. Johnson MJ, May CR. Promoting professional behaviour change in healthcare: what interventions work, and why? A theory-led overview of systematic reviews. BMJ Open 2015;5:e008592.

41. Hoddinott P, Britten J, Pill R. Why do interventions work in some places and not others: a breastfeeding support group trial. Soc Sci Med 2010;70:769-78.

42. Jacobs RL, Russ-Eft D. Cascade training and Institutionalizing organizational change. Adv Dev Hum Resour 2001;3:496-503.

43. Bracher M, Murphy J, Steward K, et al. What factors promote or inhibit implementation of a new procedure for screening and treatment of malnutrition in community settings? A prospective process evaluation of the Implementing Nutrition Screening in Community Care for Older People (INSCCOPe) project (UK). BMJ Open 2019;9:e023362.

44. May C, Rapley T, Mair FS, et al. Normalization Process Theory Online Users' Manual, Toolkit and NoMAD instrument, 2015. Available: http://www.normalizationprocess.org 